\title{
Gestão estratégica de custos: custeio por absorção em pequenas empresas em Recife, PE, Brasil
}

\author{
Cost management strategy: absorption costing in the small businesses in \\ Recife, PE, Brazil
}

\section{Gestion stratégique des coûts: méthode du coût petites enterprises dans Recife, PE, Brésil}
Gestión estrategica de costos: costeo por absorción de las pequeñas empresas en Recife, PE, Brasil

\author{
Fúlvia Fernanda de Lima* \\ (fulvia_fernanda@hotmail.com) \\ Rodolfo Araújo de Moraes Filho* \\ (rodolfoamfilho@yahoo.com.br)
}

Recebido em 11/03/2016; revisado e aprovado em 12/04/2016; aceito em 27/04/ 2016

DOI: http:/ / dx.doi.org/10.20435/1984-042X-2016-v.17-n.3(14)

\begin{abstract}
Resumo: A pesquisa objetivou verificar na gestão de custos, a aplicação do custeio por absorção em microempresas. Caracteriza-se o estudo como descritivo de natureza qualitativa. A coleta de dados foi realizada por meio de análise de documentos e aplicação de questionário para uma amostra constituída por escritórios de advocacia na cidade de Recife. Constatou-se que o tamanho da empresa e formação de centro de custo refletem a escassez da aplicação dos métodos de custeio nessas empresas. Dessa forma, o assunto em referência estrutura-se nas definições, vantagens e desvantagens do método de custeio por absorção nas microempresas.
\end{abstract}

Palavras-chave: gestão de custos; custeio por absorção; pequenas empresas.

Abstract: The research aimed to check on cost management, the application of absorption costing in microenterprises. It characterized the study as descriptive qualitative. Data collection was conducted through analysis of documents and questionnaire to a sample of law firms in the city of Recife. It was found that the size of the company and cost center training reflect the scarcity of application of costing methods these companies. Thus, the subject in question is structured in definitions, advantages and disadvantages of cost method absorption in microenterprises.

Key words: costs management; absorption costing; small businesses.

Résumé: Cette étude visait à examiner et I'application de La méthode du coût dans les micro et petites entreprises, I'objet d'étude. Cette étude est caractérisé comme descriptive et qualitative. La collecte des données a été réalisée grâce à I'analyse de documents et un questionnaire à un échantillon de cabinets d'avocats dans la ville de Recife.Il a été constaté que la taille de I'entreprise, la formation de centre de coûts reflète le manque d'application des méthodes de financement de ces entreprises. Ainsi sujet en question est structuré dans les définitions, les avantages et les inconvénients de la méthode d'établissement des coûts par I'absorption de les micro-entreprises. Mots-clés: gestion de coûts; coûts d'absorption; petites entreprises.

Resúmen: La investigación tuvo como objetivo comprobar em La gestión de costes, La aplicación de costeo por absorción em microempresas. Se caracteriza el estúdio como cualitativa descriptiva. La recolección de datos se realizo mediante el análisis de los documentos y el cuestionario a uma muestra de bufetes de abogados em La ciudad de Recife. Se encontro que el tamaño de La empresa y La formación de centros de coste reflejan La escasez de aplicación de los métodos de cálculo de estas empresas. Por lo tanto, el tema em cuestión se estructura em lãs definiciones, lãs ventajas y desventajas de costo absorción método em microempresas.

Palabras clave: la gestión de costes; costeo absorbente; pequeñas empresas.

\footnotetext{
* Universidade Federal Rural de Pernambuco (UFRPE), Recife, Pernambuco, Brasil.
} 


\section{INTRODUÇÃO}

Na atualidade é possível perceber a utilização da gestão de custos mais desenvolvida nas empresas de médio e grande portes devido ao maior investimento por meio de profissionais capacitados, novos sistemas integrados e indicadores que se alinham conforme o perfil da empresa e do controller.

Em outro cenário, encontram-se as microempresas, portadoras de menos recursos. Em julho de 2014, o Serviço Brasileiro de Apoio às Micro e Pequenas Empresas (SEBRAE) publicou o Manual de Participação das Micro e Pequenas Empresas na Economia Brasileira e informou que as micro e pequenas empresas já são as principais geradoras de riqueza no comércio no Brasil (53,4\% do Produto Interno Bruto [PIB] deste setor). No PIB da indústria, a participação das micro e pequenas $(22,5 \%)$ já se aproxima das médias empresas (24,5\%). E no setor de Serviços, mais de um terço da produção nacional $(36,3 \%)$ têm origem nos pequenos negócios. Ainda segundo o SEBRAE, esta participação aumentou tanto em serviços como no comércio, tendo se reduzido um pouco na atividade industrial, na qual predominam médias e grandes empresas que se beneficiam de economias de escala.

Nesse âmbito, a permanência das microempresas no mercado depende de muitos fatores adequados às suas necessidades respeitando as limitações de investimento. Entre as dificuldades encontradas destacam-se: conceber a diferença entre gastos e custos, classificar os custos e organizá-los em planilhas para mapeá-los de maneira objetiva e eficaz.

Diante disso, a escolha deste tema justifica-se pela preocupação com a qualidade de controle de custos aplicada e pela necessidade encontrada em diversas microempresas em identificar os gastos, classificá-los em custos e despesas, aplicar maior controle de custos a partir de métodos de custeio para entender o re- flexo desses custos na relação de oferta e demanda, e compartilhar conhecimentos diversos sobre o método de custeio por absorção e sua importância na tomada de decisão das empresas no cenário atual.

É oportuno destacar uma citação de Padoveze (2012): “Os métodos de custeio representam o processo de identificar o custo unitário de um produto ou serviço ou de todos os produtos e serviços de uma empresa, partindo do total dos custos diretos e indiretos".

Computar ou não elementos na mensuração de custos torna os métodos de custeio diferentes entre si, possibilitando assim diversas alternativas de decisão, dependendo, dessa maneira, fundamentalmente das necessidades dos usuários (GUERREIRO, 2011, p. 4).

Dessa forma, o método por absorção é facilmente implantado, pois todos os custos são absorvidos pelo custo unitário. Essa apropriação de todos os custos (diretos e indiretos, fixos e variáveis) causados pelo uso de recursos da produção aos bens elaborados, e só os de produção, se dá dentro do ciclo operacional interno. Todos os gastos relativos ao esforço de fabricação são distribuídos para todos os produtos feitos.

No controle fiscal, o Custeio por Absorção é muito importante para os controllers, pois as empresas são obrigadas a apresentar suas demonstrações para o "fisco" utilizando esse critério. No Brasil, esse sistema de custeio é o único aceito pela legislação.

Como contribuição, apresenta-se a aplicação do método de custeio por absorção adequada ao cenário das microempresas evidenciando etapas do método e análise de informações. Dessa forma, as microempresas apresentam dificuldade em estabelecer uma concordância entre seus gastos, principalmente no que concerne à separação e classificação de custos e despesas, assim são apresentados conceitos e as principais diferenças segundo a contabilidade. 
Ao explicar a separação e classificação de custos e despesas, a base do estudo se desenvolve rapidamente, pois os custos serão tratados, diretos e indiretos, respectivamente e em seguida as despesas. Nessas etapas, são apresentados quadros organizadores que consideram uma microempresa fictícia prestadora de serviços.

Visando ao aprofundamento do estudo, é relatada a análise de resultados a partir do estudo passo a passo da aplicação do custeio por absorção em que são observados novos modelos de controle de custos considerando os poucos recursos adotados pelas microempresas com a finalidade de agregar condições necessárias ao microempresário na sua gestão de custos.

\section{FUNDAMENTAÇÃO TEÓRICA}

\subsection{Micro e Pequenas Empresas}

As microempresas têm uma incidência significativa da fatia de mercado, e sua participação cresce gradativamente, embora apresentem menos recursos, vendam poucos volumes, menos funcionários, investimentos, têm papel essencial para a economia do país, principalmente no que concerne à empregabilidade, assim, norteiam alguns setores mais vulneráveis economicamente.

Uma das causas desse aumento é a saída da informalidade de algumas microempresas por meio de incentivos fiscais do governo federal. Ao passo que a carga tributária dessas microempresas é reduzida, novas empresas surgem da informalidade.

O SEBRAE apresenta outra característica na qual define microempresas aquelas com até nove funcionários, para comércio e serviços, e até 19 funcionários, no setor de construção e industrial conforme o Quadro 1 a seguir:

\begin{tabular}{|c|c|c|}
\hline \multirow{2}{*}{ Porte } & \multicolumn{2}{|c|}{ Setores } \\
\hline & Indústria & Comércio e Serviços \\
\hline Microempresa & Até 19 pessoas ocupadas & Até 9 pessoas ocupadas \\
\hline Pequena empresa & De 20 a 99 pessoas ocupadas & De 10 a 49 pessoas ocupadas \\
\hline Média empresa & De 100 a 499 pessoas ocupadas & De 50 a 99 pessoas ocupadas \\
\hline Grande empresa & 500 pessoas ocupadas ou mais & 100 pessoas ocupadas ou mais \\
\hline
\end{tabular}

Quadro 1 - Classificação de empresas segundo porte

Fonte: SEBRAE.

Elaboração: Departamento Intersindical de Estatística e Estudos Socioeconômicos (DIEESE).

No setor de indústria, as mesmas definições foram utilizadas para o setor da construção e, no setor de comércio e serviços, o setor serviços não inclui administração pública e serviço doméstico.

Foram excluídas divisões relacionadas à agropecuária, devido ao fato de este setor encontrar-se sub-representado na Rais. Parte expressiva dos produtores rurais não necessita registrar seu empreendimento como pessoa jurídica, bastando para realizar sua atividade, registrar-se no âmbito das secretarias de estado da fazenda. (SEBRAE, 2013, p. 17).

As microempresas também são definidas segundo critério de receita bruta anual de acordo com a Lei Complementar 139/2011, ao enquadrá-las com base em sua receita bruta anual.

Em decorrência da escolha de um método de custeio que esteja adequado às suas necessidades, as microempresas 
precisam analisar as características internas (organizacionais) e as características externas (contextuais) para obter uma ferramenta gerencial no auxílio ao controle e planejamento da tomada de decisão.

\subsection{Gastos}

\subsubsection{Conceitos de gastos}

As microempresas precisam da eficiência no controle de custos para conceber um painel de informações relevantes à sua saúde financeira e contábil; assim é necessário identificar e classificar seus gastos e onde os custos estão ocorrendo.

Gastos ou dispêndios: sacrifício da empresa para obtenção de bens/ serviços. Segundo a Contabilidade, em última instância, são classificados em custos e despesas, dependem do grau de importância da elaboração de bens / serviços (BRUNI; FAMA, 2012, p. 6).

Despesas são gastos com bens e serviços não utilizados nas atividades produtivas e consumidos com a finalidade de obtenção de receitas. Custo é um gasto, ou seja, um sacrifício econômico para aquisição de bens ou serviços, utilizados na produção de outros bens ou serviços, relacionados com a atividade de produção (MARTINS, 1998, p. 25).

\subsubsection{Diferença contábil entre custos e despesas}

Custos podem ser diferenciados de despesas conforme a Figura 1. Gastos incorridos para a elaboração do produto são contabilmente classificados como custos, já os gastos incorridos após a disponibilização do produto devem ser classificados como despesa.

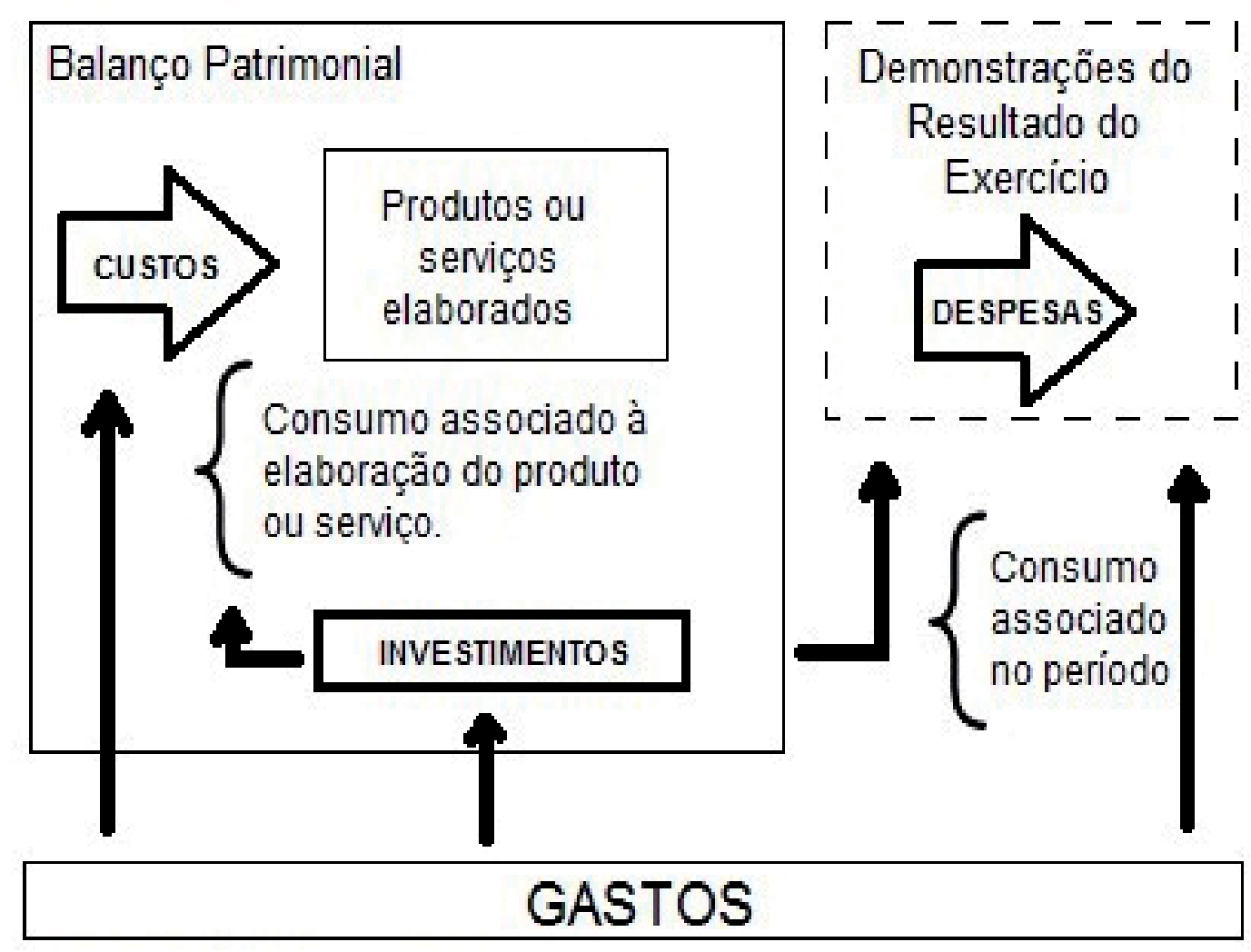

Figura 1 - Diferenciação entre custo e despesa Fonte: Bruni e Fama (2012, p. 06). 
Nesse conceito, uns gastos podem ser considerados investimentos antes da produção de bens ou serviços. No processo de transformação de gastos, enquanto os produtos ficam estocados, os custos são ativados. Vale salientar que as despesas possuem natureza não fabril. Dessa forma, elas estão associadas ao momento de seu consumo ou ocorrência, por isso são temporais.

Vale lembrar que o método de custeio por absorção exige que os custos sejam classificados como diretos ou indiretos. Assim os resultados apresentados sofrem influência do volume de produção.

Nesse sentido, os custos diretos são definidos como os custos que podem ser identificados e apropriados a um determinado departamento, centro de custo ou produto, e os custos indiretos são custos relacionados à produção que não podem ser separados economicamente entre as unidades que estão sendo produzidas, ou seja, devem ser apropriados segundo determinado critério de rateio.

\subsection{Custeio por absorção}

\subsubsection{Definição de métodos de custeio}

Os métodos de custeio estão relacionados à forma de atribuição dos custos aos produtos/serviços ou outros objetos, tais como: clientes, regiões, canais de distribuição etc. São adotados visando a orientar a tomada de decisões na escolha da melhor alternativa para a solução de um problema e, se necessário, efetivar ações corretivas, em caso de resultados não planejados (FARIA; COSTA, 2005, p. 237).

Segundo Schoute (2009, p. 222), um projeto ideal para utilização de métodos de custeio deve variar de acordo com suas finalidades pretendidas, tendo como foco os benefícios específicos associados às alternativas de escolha (ABERNETHY et al., 2001, p. 277).

Diante da necessidade de registrar as informações sobre as transações, segundo Martins (2003), é comum as empresas adotarem sistemas de custos repentinamente, acreditando em resultados imediatos. Porém, na realidade, as empresas deparam-se com um formato que, em muitos casos, não condiz com sua realidade empresarial, pois não consegue chegar aos resultados esperados, assim, o sistema não responde positivamente aos gestores.

\subsubsection{Definição do custeio por absorção}

O custeio por absorção é um sistema elaborado a partir da aplicação dos conceitos básicos da contabilidade e que consiste na apropriação de todos os custos de produção aos produtos desenvolvidos, assim como todos os demais gastos relativos ao esforço aplicado na produção (MARTINS, 2003). Este método implica a separação de custos e despesas e, consequentemente, a apropriação dos custos indiretos, por meio de rateio, aos produtos, bem como seus custos diretos (KAPLAN; COOPER, 1998). Dessa forma, vale destacar que o custeio por absorção reconhece todos os custos de produção como despesas somente no momento da venda, demonstrando de forma mais apropriada a relação da receita com a despesa, na apuração do resultado.

Horngren, Foster e Datar (2000) conceituam custeio por absorção como “o método de custeio de estoque em que todos os custos, variáveis e fixos, são considerados custos inventariáveis, ou seja, o estoque absorve todos os custos de fabricação".

Segundo Megliorini (2001) o custeio por absorção é o sistema de custeio que consiste em atribuir aos produtos fabricados todos os custos de produção, quer de forma direta ou indireta (rateios). Assim, todos os custos, sejam eles fixos ou variáveis, são absorvidos pelos produtos.

A metodologia de custeamento pelo método da absorção é considerada como básica para a avaliação de estoques pela 
contabilidade financeira para levantamento do balanço patrimonial e demonstração de resultados para atender as exigências da contabilidade fiscal e societária (SLOMSKI; BATISTA; CARVALHO, 2003, p. 13).

Pong e Mitchell (2006) alegam que o Custeio por Absorção recebe maior importância em razão da difusão dos Padrões Internacionais de Contabilidade (IASB), que adota este método de custeio sem argumentos fundamentados. É o único método válido para fins de obtenção do Quadro Demonstrativo de Resultados dos exercícios fiscais e vai ao encontro de leis tributárias brasileiras e outras tantas internacionais (DUBOIS, 2009, p. 129).

A Figura 2 abaixo foi extraída do livro Contabilidade Gerencial de Padoveze (2004) e representa a localização do custeio por absorção impetrado entre os métodos de custeio mais usuais.

\begin{tabular}{|c|c|c|c|c|c|c|c|}
\hline \multicolumn{8}{|c|}{ Gastos Totais - Diretos e Indiretos } \\
\hline \multicolumn{3}{|c|}{ Tipos de Gastos } & \multicolumn{5}{|c|}{ Métodos de Custeio } \\
\hline \multicolumn{3}{|c|}{ Matéria-prima, Materiais Diretos e Embalagens } & 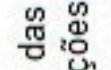 & \multirow{3}{*}{ 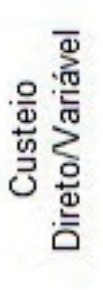 } & \multirow{5}{*}{ 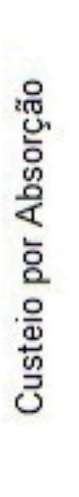 } & \multirow{7}{*}{ 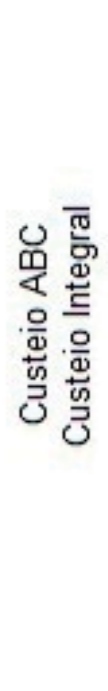 } & \multirow{8}{*}{$\frac{3}{\alpha}$} \\
\hline Despesas & s (Exemplo & Ses) & 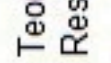 & & & & \\
\hline Mão-de-Ob & & & & & & & \\
\hline \multicolumn{3}{|c|}{ Despesas Gerais Industriais } & & & & & \\
\hline \multicolumn{3}{|c|}{ Depreciação } & & & & & \\
\hline \multicolumn{6}{|c|}{ Mão-de-Obra Administrativa/Comercial } & & \\
\hline \multicolumn{3}{|c|}{ Despesas Administrativas/Comerciais } & & & & & \\
\hline \multicolumn{3}{|c|}{ Despesas Financeiras } & & & & & \\
\hline \multicolumn{8}{|c|}{ Gastos Totais + Método de Custeio } \\
\hline$\forall$ & $\sqrt{3}$ & $\sqrt{7}$ & & & & & t6 \\
\hline $\begin{array}{l}\text { Produto/ } \\
\text { Serviço } 1\end{array}$ & $\begin{array}{l}\text { Produto/ } \\
\text { Serviço } 2\end{array}$ & $\begin{array}{l}\text { Produ } \\
\text { Serviç }\end{array}$ & & & & & $\begin{array}{l}\text { oduto/ } \\
\text { erviço } 5\end{array}$ \\
\hline
\end{tabular}

Figura 2 - Métodos de custeio

Fonte: Padoveze (2004, p. 138).

\subsubsection{Tipos de Custeio por Absorção}

O sistema de custeio por absorção pode ser com ou sem departamentalização.

- Custeio sem Departamentalização:

Pode-se perceber no esquema abaixo que o custeio sem departamentalização passa por três passos básicos: separação de custos e despesas; apropriação dos custos diretos e apropriação dos custos indiretos. Conforme Martins (2000), o custeio sem departamentalização propicia uma distribuição mais racional dos custos indiretos, uma vez que os custos são rateados nos produtos. 


\section{- Custeio com Departamentalização}

O sistema de custeio por absorção com departamentalização possui seis passos a seguir:

a) separação de custos e despesas;

b) apropriação dos custos diretos;

c) apropriação dos custos indiretos aos departamentos;

d)rateio dos custos indiretos comuns e dos gastos da administração da produção aos departamentos;

e) escolha da sequência de rateio dos custos acumulados nos departamentos de serviços;

f) distribuição aos demais departamentos e atribuição dos custos indiretos dos departamentos de produção aos produtos, de acordo com o critério escolhido.

\subsubsection{Vantagens e desvantagens do custeio} por absorção

O sistema de custeio por absorção possui as seguintes vantagens, segundo Padoveze (2004): sileira.

- É permitido pela legislação bra-

- Pode-se apurar o custo por centro de custo, uma vez que sua aplicação exige a organização contábil nesse sentido, possibilitando o acompanhamento do desempenho de cada área; e absorve todos os custos de produção, permitindo a apuração do custo total de cada produto.

Entre as vantagens, Padoveze (2000) também considera que a mais óbvia vantagem do custeamento por absorção é que ele pode ser menos custoso de aplicar, pois ele não requer a separação dos custos de manufatura nos componentes fixos e variáveis;

Para Leone (2000), a principal vantagem está no fato de o resultado pelo custeio por absorção ser aceito para a preparação de demonstrações contábeis de uso externo e para obtenção de soluções de longo prazo, em que, normalmente, as informações do custeio por absorção são indicadas.
Maher (2001) destaca também que o custeio variável apresenta separação dos custos e despesas em fixas e variáveis, facilitando as atividades de planejamento e controle, o cálculo da margem de contribuição auxilia o acompanhamento da análise do desempenho dos produtos, cria as condições necessárias para a implementação de instrumentos como o custo-padrão e dá suporte às decisões gerenciais.

Das desvantagens do custeio por absorção, tem-se a descrição segundo Wernke (2004): a principal desvantagem do custeio por absorção é no momento da utilização dos rateios para distribuir os custos entre os departamentos e/ou produtos. Em alguns momentos, tais critérios não são objetivos, podendo distorcer os resultados, beneficiando alguns produtos.

Ainda sobre as desvantagens, Souza e Clemente (2007) teorizam que o grande problema desse sistema de custeio está no momento de determinar os critérios de rateio aplicados, bem como na dedução das despesas diretamente do resultado. Essa dualidade do método pode criar situações dúbias ou mesmo encobrir resultados de acordo com a forma de apropriação dos custos e despesas.

Esse método de custeio deve ser utilizado obrigatoriamente pela legislação brasileira (MARTINS, 2003). A obrigatoriedade faz com que as organizações, se desejarem implantar outro sistema de custeio, devem adotá-lo de forma paralela. Além das dificuldades iniciais incorridas em qualquer implantação de uma nova metodologia de trabalho, esse fato transforma-se em uma barreira, considerando-se a necessidade de aumento dos recursos disponíveis para a manutenção de dois sistemas de custeio.

\section{METODOLOGIA}

Esta pesquisa é caracterizada como estudo exploratório, proporcionando uma maior familiaridade à identificação do método de custeio por absorção. 
Para o desenvolvimento da metodologia, foram realizadas pesquisas bibliográficas em diversas fontes como: livros, sites, artigos, bem como entrevistas com os responsáveis pelas informações gerenciais da empresa e observação dos dados (custos, despesas, receitas) dos questionários respondidos.

O questionário foi dividido em três partes:

- Informações Técnicas da Empresa

- Informações sobre Custeio

- Informações Práticas

\subsection{Seleção da amostra}

O universo da pesquisa é composto por escritórios de advocacia na cidade do Recife, PE. A amostra selecionada é representada por 10 escritórios localizados no bairro do Espinheiro. Os casos selecionados para o estudo seguiram o critério de acessibilidade em uma amostra intencional não probabilística.

Os atores envolvidos na pesquisa foram os diretores dos escritórios selecionados e funcionários responsáveis pela Contabilidade ou área financeira. Estes responderam a um questionário sobre custeio e informações práticas. Dessa forma, a análise dos dados qualitativos se deu mediante a técnica de análise de conteúdo a partir de documentos e periódicos.

\subsection{Estrutura do questionário}

A primeira parte do questionário compreende as informações técnicas da empresa com questões sobre a quantidade de funcionários, quais os departamentos e se o setor de contabilidade é terceirizado ou próprio.

A segunda parte foi composta em questões fechadas a fim de avaliar se a empresa possui método de custeio, em caso afirmativo, foram informados quais os métodos utilizados, bem como se a empresa divide os custos por centro de custo e se possui um colaborador com a função de controller.

Na terceira parte do questionário, foram aplicadas duas questões abertas: "quais são os principais cuidados para manter a eficiência da Gestão de Custos em um escritório de advocacia?" e "Quais são as vantagens e desvantagens do método de custeio para um escritório de advocacia?".

\section{RESULTADOS E DISCUSSÃO}

Após a aplicação do questionário, foram apurados os resultados a seguir:

- O número de funcionários varia de 1 a 20. A maioria possui apenas o diretor como funcionário, os demais advogados e setores são registrados com contratos terceirizados.

- A maioria dos escritórios divide-se em departamento administrativo e jurídico.

- Das dez empresas estudadas, apenas uma possui contabilidade própria.

- Apenas duas (as maiores) empresas aplicam métodos de custeio, uma aplica o custeio variável, e outra, o custeio por absorção.

A respeito da terceira parte analisada pelo questionário, obtiveram-se as seguintes respostas sobre quais são os principais cuidados para manter a eficiência da Gestão de Custos em um escritório de advocacia:

- É preciso atentar bastante ao custo de pessoal e prestação de serviço e seus respectivos encargos;

- É necessária a criação de mecanismos de controle e análise do comportamento dos custos.

- É preciso separar despesas pessoais das profissionais e manter o controle.

O questionário foi finalizado com a seguinte questão: "quais são as vantagens e desvantagens do método de custeio para um escritório de advocacia?". Das 
vantagens apresentadas, foram citadas: eficiência na produção e aumento da produtividade, segurança e estabilidade para entender os custos reais do escritório e identificar o resultado gerado pelo centro de custo. Das vantagens citadas, pode-se destacar a redefinição do mix de serviços.

As etapas do custeio por absorção precisam ser detalhadas e adaptadas à realidade da microempresa, ou seja, o método apresentará variações de acordo com o ramo de atividade, se é prestadora de bens ou serviços, se os serviços são de comercialização, importação ou exportação, e demais características.

A partir da definição de custos e despesas, faz-se necessária a organização das despesas gerais. Abaixo segue um modelo da empresa fictícia A, que indica uma posição financeira anual para microempresas, sinalizando o percentual de despesas e o percentual de rentabilidade para nortear o empresário sobre a balança entre receitas e despesas.

\begin{tabular}{|l|l|l|l|l|l|}
\hline \multicolumn{5}{|c|}{ POSIÇÃO FINANCEIRA ANUAL } \\
\hline \multicolumn{5}{|c|}{ ANÁLISE DE RESULTADOS DE FATURAMENTO ANUAL } \\
\hline PERÍODO & RECEITAS & DESPESAS & SALDO & $\begin{array}{c}\text { PERCEN- } \\
\text { TUAL (\%) DE } \\
\text { DESPESAS } \\
\text { (DESP X REC) }\end{array}$ & $\begin{array}{c}\text { PERCENTUAL } \\
\text { (\%) DE RENA- } \\
\text { TABILIDADE } \\
\text { (SALDO X REC) }\end{array}$ \\
\hline JANEIRO & & & & & \\
\hline FEVEREIRO & & & & & \\
\hline MARÇO & & & & & \\
\hline ABRIL & & & & & \\
\hline MAIO & & & & & \\
\hline JUNHO & & & & & \\
\hline JULHO & & & & & \\
\hline AGOSTO & & & & & \\
\hline SETEMBRO & & & & & \\
\hline OUTUBRO & & & & & \\
\hline NOVEMBRO & & & & & \\
\hline DEZEMBRO & & & & & \\
\hline TOTAL & & & & & \\
\hline
\end{tabular}

Quadro 2 - Posição financeira anual para uma empresa fictícia

Fonte: Elaboração própria.

Além de contar com as informações acima, o empresário pode se ater a detalhes em relação à média de faturamento anual com o fechamento do ano calendário. Dessa forma, fica claro, tanto em reais como em percentuais, o quanto a microempresa aumentou ou reduziu seu faturamento em relação à média anual, considerando mês a mês.

Essa explicação pode ser observada no modelo abaixo também com informações sugeridas de uma empresa fictícia A, em que mostra a evolução de seu faturamento a partir da média apurada. 


\begin{tabular}{|l|l|l|l|l|}
\hline \multicolumn{5}{|c|}{ ANÁLISE DE FATURAMENTO } \\
\hline \multirow{2}{*}{ PERÍODO } & \multirow{2}{*}{ RECEITAS } & MÉDIA 1 & \multicolumn{2}{c|}{ RESULTADO } \\
\cline { 4 - 5 } & & SEMESTRE & R\$ (REC - MÉDIA) & \% (RESULTADO R\$ x REC) \\
\hline JANEIRO & & & & \\
\hline FEVEREIRO & & & & \\
\hline MARÇO & & & & \\
\hline ABRIL & & & & \\
\hline MAIO & & & & \\
\hline JUNHO & & & & \\
\hline JULHO & & & & \\
\hline AGOSTO & & & & \\
\hline SETEMBRO & & & & \\
\hline OUTUBRO & & & & \\
\hline NOVEMBRO & & & & \\
\hline DEZEMBRO & & & & \\
\hline
\end{tabular}

Quadro 3 - Análise de faturamento mensal para uma empresa fictícia Fonte: Elaboração própria.

Ainda sobre o tratamento das despesas, as microempresas podem utilizar um simples modelo de classificação como base à organização das subcategorias. As principais categorias são: despesas administrativas, despesas de impostos, despesas de pessoal e despesas bancárias.

\subsection{Aplicação do custeio por absorção}

Na perspectiva de sugerir a aplicação do custeio por absorção para microempresas que ainda não possuem um método, são apresentadas abaixo as etapas conforme o referencial teórico estudado.
- Separação dos gastos do exercício em custos e despesas

Popularmente as microempresas definem como custo apenas os gastos de aquisição de matéria-prima ou investimento, todos os demais gastos estavam classificados como despesas, divididas em: operacionais, administrativas, bancarias e comerciais (em alguns casos).

As tabelas a seguir são modelos de controle de custos em uma microempresa (de natureza comercial) de prestação de serviços de distribuição em lojas de seis produtos. Nesse caso, é possível alocar as despesas comerciais como custos diretos, uma vez que se trata de uma empresa comercial, e os gastos ligados diretamente à venda são classificados como custos, conforme quadro 4 a seguir. 


\begin{tabular}{|l|l|}
\hline \multicolumn{1}{|c|}{ Custos Diretos e Indiretos } & \multicolumn{1}{c|}{ Despesas } \\
\hline Pessoal Administrativo & Despesa Pessoal Administrativo \\
\hline Aluguel & Despesa de Aluguel \\
\hline Sistema & Despesa de Sistema \\
\hline Veículos & Despesa de Veículos \\
\hline Viagens & Despesa de Viagens \\
\hline Materiais & Despesa de Materiais \\
\hline Gerais & Despesa Geral \\
\hline Manutenção & Despesa de Serviços Prestados \\
\hline Serviços Prestados & Despesa de Manutenção \\
\hline Depreciações & Despesa de Depreciações \\
\hline Tributários & Despesa Tributária \\
\hline Compras de Mercadorias & Despesa Financeira \\
\hline
\end{tabular}

Quadro 4 - Total dos custos e despesas

Fonte: Elaboração própria.

- Classificação dos custos em diretos e indiretos

Os gastos comerciais foram reclassificados como custos diretos, e os custos indiretos foram rateados. Tais custos estavam alocados como despesas, pois é verificado que alguns gastos classificados como despesas eram comuns a toda empresa, inclusive ao setor comercial.

Assim, algumas dessas despesas deveriam ter parte de seus valores alocados também para custos indiretos. E assim foram elaborados os custos indiretos de vendas, que anteriormente não existiam na empresa.

Na separação dos custos a seguir, é possível perceber que a maior representação dos custos desses materiais são os custos diretos, especificamente, os custos com aquisição de mercadorias.

a) Custos Indiretos: Pessoal administrativo, aluguel, sistema, veículos, viagens, materiais, manutenção, serviços prestados, depreciações e tributários.

b)Custos Diretos: Brindes e doações, Sci/ Serasa/Outros e feiras e eventos.
- Apropriação dos custos diretos a cada produto

Para identificar o custo direto de cada produto, foi necessária uma apropriação considerando o quanto cada linha representava dentro do total dos custos de aquisição. Com esses percentuais, foram obtidos os custos proporcionais de cada linha; usamos esses índices para calcular as apropriações dos demais custos diretos.

Vale ressaltar que, no relatório original, a empresa considera apenas o gasto de aquisição da mercadoria como custo e todos os demais como despesas.

Essa linha merece uma atenção especial, uma análise mais completa a fim de identificar quais são os fatores que mais influenciam os seus custos elevados. Vale ressaltar que, através dos relatórios organizacionais, verifica-se a grande representação que ela tem dentro da organização, pois domina em quantidades vendidas e em receitas brutas geradas, no entanto o alto custo promove que o lucro bruto dessa mesma linha seja relativamente baixo, se compará-lo ao custo de aquisição e as vendas dessa linha. 


\section{- Rateio dos Custos Indiretos}

A empresa separava seus gastos apenas em Custos Diretos e Despesas. Custos Diretos, os custos de aquisições e todos os demais gastos estavam alocados como despesas.

Constatou-se que algumas dessas despesas deveriam estar alocadas como custos indiretos, uma vez que, se não estivessem relacionadas diretamente a nenhuma linha de produto específica, eram gastos comuns a todas as linhas e que também eram comuns aos demais setores da empresa.

Tanto os custos diretos como indiretos estão na linha de produtos em que deverá ser analisada e gerida para que possa estudar uma melhor maneira de reduzir os seus custos, pois, ela afetará diretamente o resultado do exercício.

\section{- Tratamento das Despesas}

Nessa etapa, foram utilizados alguns dados passados por um colaborador dessa empresa. Observou-se que, embora boa parte das despesas estivesse alocada como administrativas, tais como aluguel, sistema, veículos, manutenção entre outras, grande parte das atividades da empresa estavam voltadas para o comercial.

Por isso uma parte dessas despesas foi alocada para os custos indiretos, porque, embora não estivesse ligada diretamente a área comercial, essas despesas deveriam ser repassadas aos custos dos produtos.

Como exemplo, tem-se a despesa de aluguel, uma vez que a maior parte do local onde a empresa está alojada é utilizada para a função de venda e estocagem.

As despesas administrativas apresentam grande variedade em sua divisão, por isso é de extrema importância que os gestores de micro e pequenas empresas saibam segregar essas despesas e localizar quais têm peso maior no movimento contábil mensal. a) Despesas de Pessoal Administrativo: Salários, Pró-labore, INSS, FGTS, férias, $13^{\circ}$ salário, horas extras, indenizações trabalhistas, transporte e refeição, assistência médica, contribuição sindical, bolsa-estágio, treinamento, seguro para funcionários, recrutamento e seleção, aluguel, exames médicos, premiação/ bonificação etc.

b)Despesas de Aluguel: aluguel de imóvel, equipamentos e veículos.

c) Despesas de Sistema: licença de uso de software, consultoria (implantação e acompanhamento do sistema), aluguel do software e manutenção do sistema.

d)Despesas de Veículos: combustível/ lubrificantes, manutenção de veículos e seguro.

e) Despesas de Materiais: material de expediente, limpeza, consumo e Xerox e para manutenção geral.

f) Despesas Gerais: água, energia, telefone, copa/cozinha, estacionamento/ condução, táxi, serviços de cartório e correios, bens de natureza não imobilizável, internet, associações e contribuições, assinaturas/anuidades, confraternizações/eventos e taxas administrativas.

g)Despesas de Manutenção: manutenção geral, equipamentos e veículos.

h)Despesas de Serviços Prestados: contador, advogados, segurança, serviços gráficos, de transporte e limpeza.

i) Despesas de Depreciações: depreciações e amortizações.

j) Despesas Tributárias: tributos em geral, impostos de serviços prestados, Simples Nacional, frete, diferencial de alíquota, municipais, estaduais e federais, taxas diversas, custas processuais, parcelamento/ refis e multas fiscais.

\section{- Apuração do Resultado}

A Demonstração do Resultado auxilia na organização de despesas e custos a serem deduzidos uma vez que separa por linha do produto, além de informar os principais fechamentos de contas do 
exercício, ou seja, sinteticamente nessa apuração de resultado é possível ter uma visão geral da separação dos gastos considerando as etapas realizadas pelo custeio por absorção.

\section{CONSIDERAÇÕES FINAIS}

O presente artigo demonstrou, em definições e quadros, procedimentos aplicados pelo método de custeio por absorção visando ao estudo para o cenário das microempresas, escolhidas no ramo de advocacia na cidade do Recife, PE.

Foi relatado o desenvolvimento de planilhas de acordo com a padronização de cada etapa realizada sob a ótica do custeio por absorção, visto que há contrapartidas entre separação de despesas e custos praticados e há a necessidade de realizar estudo profundo sobre o caso, concernente às decisões gerenciais de apropriação de custos aos produtos comercializados.

Através da metodologia aplicada, foi possível visualizar a dificuldade encontrada nos escritórios, principalmente os menores, a separação dos gastos e, por ventura, a escassez de aplicação de método de custeio apresentada pela maioria.

Para atender o intuito real do trabalho, que é o de facilitar o uso da contabilidade de custos pelos gestores de micro e pequenas empresas, foram feitas adaptações da teoria no sentido de mostrar aos gestores a contabilidade de custos como uma ferramenta de fácil entendimento e utilização que traz informações bastante relevantes para seus controles e decisões.

Portanto, o método estudado visa estabelecer passos simples para a organização dos gastos e receitas da empresa, tomando por base o método de custeio por absorção. São apenas passos iniciais para um maior embasamento nas tomadas de decisão, principalmente com a utilização da análise de planilhas simples que servem como verdadeiros mapas de custos e despesas.

\section{REFERÊNCIAS}

ABERNETHY, Margareth A. et al. Product diversity and costing system design choice: field study evidence. Management Accounting Review, v. 12, n. 3, p. 261-279, 2001.

BRUNI, Adriano Leal; FAMA, Rubens. Gestão de custos e formação de preços. 6. ed. São Paulo: Atlas, 2012.

DUBOIS, Alexy. Gestão de custos e formação de preços: conceitos, modelos e instrumentos, abordagem do capital de giro e da margem de competitividade. 3. ed. São Paulo: Atlas, 2009.

FARIA, A. C. de; COSTA, M. de F. G. da. Gestão de custos logísticos. São Paulo: Atlas, 2005.

GUERREIRO, Reinaldo. Estruturação de sistemas de custos para a gestão da rentabilidade. 1. ed. São Paulo: Atlas, 2011.

HORNGREN, C. T.; FOSTER, G.; DATAR, S. M. Contabilidade de custos. 9. ed. Tradução de José Luiz Paravato. Rio de Janeiro: LTC, 2000

KAPLAN, Robert S., COOPER, Robin. Custo $\mathcal{E}$ desempenho: administre seus custos para ser mais competitivo. Trad. O. P. Traduções. São Paulo: Futura, 1998.

LEONE, George Sebastião Guerra. Custos: planejamento, implantação e controle. São Paulo: Atlas, 2000.

MAHER, M. Contabilidade de custos: criando valor para a administração. São Paulo: Atlas, 2001.

MARTINS, E. Contabilidade de custos. 9. ed. São Paulo: Atlas, 2003.

. Contabilidade de custos. 8. ed. São

Paulo: Atlas, 2000.

. Contabilidade de custos. 6. ed. São Paulo: Atlas, 1998.

MEGLIORINI, Evandir. Custos. São Paulo: Makron Books, 2001.

PADOVEZE, C. L. O paradoxo da utilização do método de custeio: custeio variável por absorção. Revista CRC-SP, ano 4, n. 12, p. 4258, jun. 2000.

Contabilidade gerencial: um enfoque em sistema de informação contábil. 4. ed. São Paulo: Atlas, 2004. 
PADOVEZE, C. L. Controladoria estratégica e operacional. 3. ed. São Paulo: Cengage Learning, 2012.

PONG, Chris; MITCHEL, Falconer. Full costing versus variable costing: does the choice still matter? An empirical exploration of UK manufacturing companies 1988-2002. The British Accounting Review, v. 38, n. 2, p. 131-148, 2006.

SCHOUTE, Martijn. The relationship between cost system complexity, purposes of use, and cost system effectiveness. The British Accounting Review, v. 41, n. 4, p. 2008-226, 2009.

SERVIÇO BRASILEIRO DE APOIO ÀS MICROEPEQUENASEMPRESAS (SEBRAE). Anuário do trabalho na micro e pequena empresa. 6. ed. Brasília, DF: DIEESE, 2013.

. Participação das micro e pequenas empresas na economia brasileira. jul. 2014. Disponível em: <http://www.sebrae.com.br/Sebrae/ Portal\%20Sebrae/Estudos\%20e\%20Pesqui-
sas/Participacao $\% 20$ das $\% 20$ micro $\% 20$ e $\% 20$

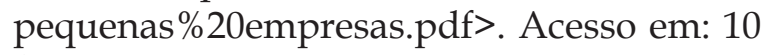
fev. 2016.

. Entenda as diferenças entre microempresa, pequena empresa eMEI.Disponível em: <http:/ / www.sebrae.com.br/sites/PortalSebrae/artigos/Entenda-as-distin \%C3\%A7\%C3\%B5esentre-microempresa,-pequena-empresa-e-MEI>. Acesso em: 27 dez. 2015.

SLOMSKI, V.; BATISTA, I. V.C.; CARVALHO, E. M. de. Os métodos de custeio variável e por absorção e o inconsciente coletivo na contabilidade de custos. Revista de Contabilidade do Mestrado em Ciências Contábeis da UERJ, v. 8, n. 1, p. 9-20, 2003.

SOUZA, Alceu; CLEMENTE, Ademir. Gestão de custos. Aplicações operacionais e estratégicas. São Paulo: Atlas, 2007.

WERNKE, Rodney. Gestão de custos: uma abordagem prática. 2. ed. São Paulo: Atlas, 2004.

\section{Sobre os autores:}

Fúlvia Fernanda de Lima: Mestranda no Programa de Pós-graduação em Administração e Desenvolvimento Rural (PADR) pela Universidade Federal Rural de Pernambuco (UFRPE). E-mail: fulvia_fernanda@hotmail.com

Rodolfo Araújo de Moraes Filho: Professor Associado II da área de Administração da Universidade Federal Rural de Pernambuco (Departamento de Administração [DADM] e Programa de Pós-graduação em Administração e Desenvolvimento Rural [PADR]). Pós-Doutorado em Administração e Gestão Territorial pela Université Pierre Mendes France (UPMF). E-mail: rodolfoamfilho@yahoo.com.br 